\title{
CONSECUENCIAS QUE TIENE EL ACOSO LABORAL DE LAS MUJERES EN MÉXICO PARA PROPONER ALTERNATIVAS DE SOLUCIÓN
}

\author{
C. Cynthia del Carmen Villacis Gerónimo ${ }^{1}$ \\ Dr. José Antonio Morales Notario ${ }^{2}$
}

Resumen: En México el acoso laboral es un problema actual ya que con la llegada de los derechos humanos en el siglo XIX con la promulgación de la Ley de Procuraduría de Pobres de 1847, la sociedad ha conocido que las personas tiene derechos y obligaciones, uno de los derechos es el buen trato en el trabajo, tener un ambiente sano y respetar y ser respetado. Al analizar las características, componentes y desarrollo del proceso del acoso laboral (mobbing) en el ámbito del trabajo, cada persona actúa con diferente responsabilidad, obligaciones y manera de pensar, cumpliendo así su desempeño de manera eficaz. Sin embargo, tiene ventajas, y desventajas ya que un trabajador (a) puede sufrir de acoso laboral o (mobbing), y veremos el comportamiento, sensibilidad y vulnerabilidad de los trabajadores a esta situación, ya que cada vez es más frecuente en los centro de trabajo y éste constituye uno de los lugares más importantes de nuestra vida, ahí pasamos el mayor tiempo del día; el empleo es básico para el crecimiento económico ya que de éste depende miles de personas y familias, ya que el salario es el sustento de muchas familias mexicanas, (Arciniega, 2017). La expresión mobbing tiene orígenes especialmente en Suecia, donde se empleó por primera vez para describir la conducta hostil del patrón hacia el trabajador. Heinz Leymann investigó el fenómeno en la década de 1980, y fue quien utilizó por primera vez el término mobbing ¿qué significa? El concepto en sí es la conducta abusiva $\mathrm{y}$, especialmente, los comportamientos, palabras, actitudes, gestos que puedan atentar la dignidad o la integridad física o psíquica de un individuo, poniendo en peligro su empleo, o degradando el ambiente de trabajo; esto sucede cuando otro

\footnotetext{
${ }^{1}$ Estudiante de la Licenciatura en Derecho de la Universidad Juárez Autónoma de Tabasco

${ }^{2}$ Dr. en Derecho. Profesor Investigador de la Universidad Juárez Autónoma de Tabasco
} 
empleado o su jefe se dedican a hostigarlo (a) Martínez León, 2012).

Palabras Claves: Mobbing, derechos, trabajador, integridad física $\mathrm{y}$ psicológica.

Abstract: In Mexico occupational harassment is a current problem; since the advent of Human Rights in the nineteenth century with the promulgation of the Poor Prosecutor Law in 1847 , society has known that people have rights and obligations, ones of the rights are the good treatment at work, to have a healthy environment and to respect and be respected. When analyzing the characteristics, components and development of the process of mobbing in the workplace, each person acts with different responsibilities, obligations and way of thinking, thus fulfilling their performance in an effective way. However, it has advantages and disadvantages as a worker someone may suffer mobbing, and we will see the behavior, sensitivity and vulnerability of workers to this situation; as it is increasingly more in the center of works and this is one of the most important places in our lives, because there we spend most time of our days;
Employment is the basis of economic growth; thousands of people and families depend on a job, since wages are the livelihood of many Mexican families, (Arciniega, 2017). The term mobbing has origins especially in Sweden, where it was first used to describe the employer's hostile behavior toward the worker. Heinz Leymann investigated the phenomenon in the 1980s, and it was he who first used the term mobbing. What does it mean? The concept itself is abusive behavior and, especially, actions, words, attitudes, gestures that may compromise the dignity or physical or mental integrity of an individual, jeopardizing their employment, or degrading the work environment; This happens when another employee or his boss is engaged in harassing him or her.

Keywords: Mobbing, rights, worker, physical and psychological integrity.

\section{INTRODUCCIÓN}

El acoso laboral es la conducta agresiva que un superior ejerce sobre un trabajador o trabajadora al grado de llegar a menospreciar y pisotear la integridad de éste. En el acoso laboral como toda relación se necesita de dos 
para que pueda existir el acoso laboral, ya que una de las partes es la que se dedica a la presión constante y la violencia que se ejerce dentro del entorno laboral. La persona que sufre este acoso puede ser atormentada con comentarios malintencionados $\mathrm{o}$ escuchar de manera recurrente críticas exageradas hasta llegar a la humillación; por lo general, la intención del acosador es que la víctima renuncie al empleo o modifique su conducta, ya que ésta resulta contraria a sus intereses. Pero el ser humano se caracteriza por utilizar su intelecto más que la fuerza física, El acoso laboral es uno de los problemas sociales que en los últimos años ha tomado mucha relevancia en nuestro país. Con anterioridad no se había clasificado como un problema social, pues aunque el empleado era tratado de manera discriminante, no tenía el derecho de opinar, mejorar, o incluso sobresalir. El acoso laboral constituye una violación a las normas del Derecho Internacional que garantiza a todo ser humano respeto por sus garantías.

\section{ACOSO LABORAL}

Al analizar la situación laboral se encuentran muchas diferencias entre la presión normal que un jefe puede ejercer sobre un empleado para el correcto desarrollo de sus actividades y el acoso laboral. Si la situación laboral se vuelve difícil pues el empleador ya no está conforme con el trabajo que realiza el empleado, éste tiene derecho a saberlo, ser cambiado de área, ser sancionado acorde a las políticas de dicha empresa y en el peor de los casos pueda ser despedido previa notificación de sus errores. Si el empleador o superior comete faltas de respeto, ya sea en privado o en público o exige el cumplimiento de metas imposibles de alcanzar y pone trabas al empleado para que no pueda desarrollar con eficacia su trabajo, el trabajador está sufriendo acoso laboral.

Cabe señalar que el trabajo se constituye como un derecho y una obligación protegida por la Constitución Política de los Estados Unidos Mexicanos en su artículo 5 y por la Ley Federal del Trabajo, en sus artículos 2 y 3 , respectivamente, ya que dichos preceptos legales exigen respeto para la dignidad y libertades de quien proporcione un servicio, ya sea hombre o mujer, independientemente de su edad, situación económica o actividad laboral a la que se dedique.

El artículo 2 reza: Las normas de trabajo tienden a conseguir el 
equilibrio y la justicia social en las relaciones entre trabajadores y patrones; en otras palabras, este articulo habla sobre la convivencia y la relación que tiene un trabajador con su superior, pero al analizarlo bien, se puede decir que en la mayoría de los casos no se llega a conseguir el equilibrio y la justicia por los abusos excesivos que ejerce el patrón a su empleado llegando a que la relación de trabajo se vuelva insoportable (Cámara de Diputados del

H. Congreso de la Unión, 1970).

En lo que se refiere al Artículo 3 se lee que el trabajo es un derecho y un deber social, o sea, cada persona necesita de éste para poder subsistir y/o mantener a su familiares, pero como el trabajo es un deber social, igual cada persona tiene derecho a que su ambiente de trabajo sea agradable y que éste pueda realizar sus actividades laborales $\mathrm{y}$ tenga como recompensa una remuneración económica que asegure un nivel económico decoroso acorde a las actividades que realice; el patrón tiene que adecuar las condiciones ambientales sin distinción de raza, género y religión, ya que cada persona tiene el derecho de poder expresarse y creer en lo que quiera $\mathrm{y}$ esto no tiene que ser motivo de discusión o discriminación hacia persona alguna, al igual que tiene que capacitar a sus trabajadores para que logren ser mejores empleados cada día (Cámara de Diputados del H. Congreso de la Unión, 1970).

Dentro de la Constitución Política de los Estados Unidos Mexicanos, el artículo 5o., reza que a ninguna persona podrá impedirse que se dedique a la profesión, industria, comercio o trabajo que le acomode, siendo lícitos. El ejercicio de esta libertad sólo podrá vedarse por determinación judicial, cuando se ataquen los derechos de terceros. Cada persona con el paso de los años va eligiendo que quiere ser a lo largo de su vida y a que se quiere dedicar. Este artículo de la Constitución Política de los Estados Unidos Mexicanos lo clasificamos dentro de los artículos de las garantías individuales, que son los derechos que por naturaleza adquirimos y que en el momento de desempeñarnos profesionalmente podemos decidir libremente a que dedicarnos sin necesidad que alguna persona nos obligue a desempeñar alguna profesión, siempre y cuando no incurra en un acto ilícito. Esto implica que los legisladores tomaron en serio esta problemática, por lo que el incluir dentro de la legislación laboral la prohibición terminante de 
cualquier tipo de discriminación para los trabajadores por motivos étnicos, sexo, edad, capacidades diferentes, condición social, religión, estado civil o cualquier otro que afecte lo que se conceptualiza como "trabajo digno o decente" y que no logre garantizar las condiciones mínimas de una relación laboral digna será castigado y no será ignorado como en ocasiones previas a la reforma. Incluso se prevé dentro de las modificaciones que las mujeres como parte de un grupo vulnerable si sufren acosos $u$ hostigamiento sexual tienen todo el apoyo al denunciar para lograr defender sus derechos (Cámara de Diputados del H. Congreso de la Unión, 1917).

La palabra motivación se puede definir como la razón para que una persona se pueda proponer un objetivo o metas para el futuro y pueda ser satisfactorio para quien se lo propone. Es una palabra de vital importancia que le da significado al incentivo de llegar a alcanzar un sueño en la vida; pero a esta palabra se le asocia de manera negativa al controversial tema del acoso laboral (mobbing), ya que tiene que haber un motivo para que se produzca el acoso laboral. El acoso laboral inicia con la pérdida del respeto y la comunicación del patrón hacia el empleado, pero al analizar esta situación, se encuentra que no solo se da entre el patrón y el trabajador, sino que también entre los mismos empleados y compañeros del trabajo.

En cada empresa hay una gran diversidad de personas y todas tienen una manera de pensar, actuar, socializar y convivir diferentes. Cuando un empleado se siente amenazado por alguien que puede sobresalir en su trabajo mejor que él, incurre a este tipo de actos desagradables para poder intimidar a un empleado o compañero de trabajo por celos, resentimiento, envidias, y llega a hostigar, menospreciar, maltratar, e inclusive agredir a la víctima, todo con el propósito que el empleado o la empleada renuncie.

Por lo tanto, la motivación y el acoso laboral (Mobbing) a pesar que son palabras contrarias, pues una significa luchar por la metas que te propongas y la otra es un acto de cobardía que tiene como fin intimidar a una persona para someterla, se coluden para ir de la mano una de la otra en el acoso laboral. La motivación se vuelve un factor decisivo puesto que motivar al acosador a denigrar y maltratar al empleado.

Se destacan tres elementos fundamentales: intensidad esfuerzo $\mathrm{y}$ persistencia, que se pueden clasificar 
como palabras de estimulación para alcanzar un bien común. La intensidad se refiere a la medida de esfuerzo que la persona utiliza para lograr un objetivo, y la persistencia es la voluntad de salir adelante. Todas estas palabras tienen un gran significado, el trabajador tiene que entender que si se propone objetivos y metas, podrá salir adelante sin necesidad que alguna persona lo menosprecie y lo desanime al insinuar que él no tiene la capacidad de lograr un trabajo. Si el trabajador conoce sus capacidades podrá lograr llegar a la meta fijada y sobrepasar todos los obstáculos que se le presenten aunque las personas no crean en su capacidad; si el empleado tiene una meta fijada podrá lograr su cometido (Robbins y Judge, 2009).

\section{ACOSO LABORAL POR GÉNERO}

El acoso laboral por motivo de genero establece como primer punto el principio de igualdad, éste es uno de los principales factores que afecta a la sociedad, pues al haber desigualdad laboral podemos entender que a lo largo de la historia la igualdad de género ha evolucionado con el paso del tiempo, pero desafortunadamente no todas las personas entienden este concepto que afecta principalmente al género femenino como grupo vulnerable $\mathrm{y}$ como consecuencia se deriva la discriminación.

La mujer ha logrado comprobar la capacidad que tiene para desempeñar actividades que antes no se le permitía hacer, rompiendo estereotipos; en la actualidad la mujer es capaz de aprender un oficio o inclusive llegar a tener una profesión, lo que antes no se le permitía. Pero la desigualdad de género sigue arraigada en la cultura en México lo que deriva en consecuencias como el acoso laboral.

La globalización económica ha traído como consecuencia la participación más activa en el ámbito laboral por parte de las mujeres, algunos consideran que han sido las más beneficiadas. Esta incorporación del género femenino en el ámbito laboral no ha estado acompañada con la erradicación de la discriminación laboral por la que tanto han luchado las mujeres.

Carrasco Fernández, (2012) cita a De Villota Paloma para definir a género como:

“... una categoría de análisis y principios básicos de la organización social que atraviesan los niveles de producción y reproducción material de cada sociedad en un momento histórico, siendo el orden de género 
circunstancia a la relación social; cualquier cambio que afecte a la sociedad, afecta a las relaciones de género".

Cuando el ambiente laboral es un caos organizacional debido a las constantes negociaciones por la jerarquía y constantes arreglos sociales $y$ modificaciones desiguales se permite el escenario propicio para el maltrato y acoso laboral, que afecta a los trabajadores más vulnerables por cuestiones de género, etnia o pertenecer a cargos de niveles bajos, pero que también se utiliza para debilitar competidores o personas con capacidad de cuestionar la autoridad en turno (Sieglin, 2016).

Debido a la cultura y tradiciones de nuestro país, México tiene un historial de violencia con condiciones negativas por actitudes $\mathrm{y}$ comportamientos agresivos contra las mujeres que van más allá de hostilidades, humillaciones y discriminación, en el ámbito laboral y que implica no sólo a los jefes superiores, sino también a los compañeros de trabajo o por, incluso, personal bajo el mando de ellas.

Estas dinámicas agresivas en el trabajo les dan la ventaja a los superiores sobre las mujeres que buscan desarrollarse laboralmente por el anhelo de mejorar su situación económica o en aquellas que son jefas de familia y de quien depende por completo la manutención del hogar. Dentro de los acosos que sufren las mujeres se hallan los acercamientos o presiones sexuales, tanto físicas como verbales condicionando la hostilidad del ambiente laboral y las oportunidades de empleo, discriminándola con menores opciones, promociones y prestaciones. En este punto, en el ámbito nacional las mujeres han sufrido violencia de un colega un $22.6 \%$ de mujeres de 15 y más años de edad, un $91.3 \%$ dijo ser víctima de discriminación y $19.3 \%$ de acoso entre los años 2011 al 2015 (Instituto Nacional de Estadística y Geografía [INEGI], 2011).

Cuando se habla sobre que la persona que ejerce la violencia sobre las mujeres es el patrón o jefe o compañeros de trabajo o de la escuela, maestros o autoridades, escolares, las entidades que registraron mayor porcentaje de violencia en mujeres fueron Nayarit y Veracruz de Ignacio de la Llave con 4.8 $\%$, seguido por Campeche y Querétaro con $4.4 \%$ y $4.3 \%$ pero 21 entidades manejan indicadores de violencia superiores al promedio nacional, o sea un $2.9 \%$. Donde se identificaron agresiones extremas que les afectaron la salud 
mental y autoestima, agudizadas porque hacen responsables a las mismas mujeres en base a que manejan conductas inapropiadas de acuerdo a los comportamientos aceptados de dominación masculina, como el acudir a ciertos lugares, salir a determinadas horas, vestirse o comportarse de cierta manera. Tabasco se considera uno de los estados con un indicador superior al promedio nacional de violencia extrema hacia las mujeres, que incluyen entre ellos la violación y la prostitución. De hecho de 267, 931 mujeres de 15 o más años de edad en Tabasco que trabajan, $23.8 \%$ indica que padeció violencia y de éste porcentaje, el $25.4 \%$ eran casadas, un $23.9 \%$ estuvieron unidas a alguien y el $19.8 \%$ eran solteras. Y de ellas surge un indicador de 13045 mujeres que han vivido acoso laboral, o sea un $20.5 \%$, lo que vulneró su situación económica, pues no se le reconocían sus esfuerzos y trabajo y se le bloqueó en el alcance de oportunidades de superación, mermando también su posición en la familia, pues este círculo vicioso afecta su desenvolvimiento en ambos ámbitos, ya que si no gana dinero por cuidar a su familia, debe cuidar a su familia por no ganar dinero. Estos números posicionan a Tabasco en el lugar número 13 de entidades con violencia hacia la mujer en el ámbito laboral. En la actualidad, los hombres continúan manteniendo los espacios más altos en la estructura organizacional, lo que les facilita el poder presionarlas discriminándolas y al igual que sus compañeros de trabajo, acosarlas y humillarlas mermando su verdadero desenvolvimiento en el trabajo e inclusive reduciéndoles su salario y prestaciones, así como oportunidades de ascenso. Se sigue bloqueando a las mujeres en su desarrollo profesional pues se mantiene la idea tradicional que la mujer por su papel reproductor se le encasilla y estereotipa en actividades referentes al cuidado de los hijos y la familia, excluyéndola de las económicas, culturales y políticas. A pesar de las reformas a la ley laboral y modificaciones legislativas en Tabasco el $58.0 \%$ de las mujeres tienen menos oportunidades de ascender de nivel que un hombre, a $31.1 \%$ le pidieron la prueba de embarazo y a $17.0 \%$ les redujeron el salario, despidieron o no son contratadas, por cuestiones de edad o estado civil. También a un $53.5 \%$ de las mujeres que trabajan y sufren discriminación les pagan menos que a los hombres por el mismo trabajo o puesto. Y que el 38.4\% la violencia la sufren en instituciones públicas, el $37.1 \%$ en 
fábricas o talleres y el $31.1 \%$ en empresas privadas o bancos; éste indicador demuestra la incongruencia existente en el gobierno, pues las instituciones públicas son las que deberían cuidar las reformas y estipulaciones realizadas para la protección de los derechos humanos de las mujeres. Estas agresiones se dieron mayormente por un compañero de trabajo en un $64.7 \%$ y por un patrón o jefe en un $50.9 \%$. Y lo triste de la situación que es reflejo de la cultura mexicana es que el hecho de trabajar no le brinda méritos o beneficios en su hogar, pues casi la mitad de las mujeres casadas o unidas, un $46.5 \%$ que sufren violencia en el trabajo, también la sufren en el hogar por parte de su pareja (INEGI, 2011).

\section{CARACTERÍSTICAS}

CONSECUENCIAS DEL ACOSO

\section{LABORAL}

El acoso se caracteriza por comportamientos que afectan y amenazan su estatus profesional, aunado a las amenazas personales, un aislamiento provocado para manipular más a las víctimas, la carga excesiva de trabajo, que en ocasiones es intrascendente y una desestabilización, los cuales son una muestra de los abusos $\mathrm{y}$ arbitrariedades por parte del empleador o representantes. Aunque existen varios tipos de acosos dependiendo de la relación entre el acosador y la víctima. El más frecuente es el denominado acoso moral vertical porque se da entre el empleador o quien ejerce la autoridad y el empleado, pues utiliza de su categoría o sus facultades para doblegar y someter al trabajador; esta el acoso moral horizontal que se trata del grupo de trabajadores que desarrollan una actitud activa y el trabajador víctima que se desenvuelve de manera pasiva y que cuentan con una misma jerarquía y tiene como propósito perjudicar a la víctima para impedirle su ascenso, pues lo consideran peligroso para ellos; y, finalmente está el acoso moral mixto, en el que se combinan tanto las actitudes agresivas de los compañeros de trabajo como la actitud de complacencia del empleador y que juntos atosigan a la víctima que tolera este tipo de situaciones (Arciniega, 2009).

Al analizar las características, componentes y desarrollo del proceso del acoso laboral (mobbing) no se refiere a situaciones de estrés laboral, pues hay una amplia diferencia entre los conflictos habituales y los incidentes puntuales en las relaciones de trabajo. 
Éstos se entienden como aspectos de la cotidianeidad laboral y no conforman acoso. Sin embargo, según Cortés Villegas (s. f.) citando a Leymann, se identifican cuarenta y cinco conductas que constituyen mobbing, y de ellas se deslindan cinco fases en que el acoso que sufre la víctima en el entorno laboral se desarrolla:

La Comunicación es la primera de las etapas que se notan, en dónde no se le permite expresarse correctamente al trabajador y constantemente se realizan amenazas verbales en su persona, llegando al punto en que la víctima decide abandonar el empleo y finalizar el acoso.

La afectación social, en esta etapa el entorno se vuelve hostil teniendo que laborar en total aislamiento, pues los compañeros de trabajo evitan ser relacionados con el trabajador acosado por miedo a sufrir la misma situación, incrementando el sentimiento de discriminación, aunado a chismes, malos tratos $\mathrm{o}$ comentarios, insultos $\mathrm{O}$ indiferencia (Cortés Villegas (s. f.).

En la etapa del Desprestigio Personal, las burlas, ridiculizaciones, rumores y demás comportamientos discrepantes hacia el trabajador logran afectar su imagen y reputación, a grado tal que el trabajador ve mermada su autoestima y su capacidad de desarrollo.

La siguiente etapa es la del Descrédito laboral, en la que el trabajador acosado debido a la afectación psicológica que vive sufre un deterioro en su desempeño laboral, pues se ve relegado en la asignación de tareas y actividades por no considerarlo capaz y apto, lo que en determinado momento termina por creerlo.

La Afectación de la salud es la etapa final de esta situación; es cuando el trabajador o trabajadora sufre, además, acoso sexual, volviendo su área de trabajo un ambiente peligroso, pues se puede sufrir agresiones físicas, además de las psicológicas y sociales (Cortés Villegas (s. f.).

El desarrollo del proceso del acoso laboral está basado en las conductas de hostilidad que el agresor le trasmite a la víctima; estas prácticas suceden de forma sistemática en un extenso periodo de tiempo para que la víctima de acoso laboral afronte agresiones que van creciendo con intensidad y frecuencia y éste llegue a un punto de desesperación y estrés, generando un ambiente de trabajo lleno de incomodidad.

El acoso es una forma de violencia que a pesar de ser destructiva 
puede pasar inadvertida ¿Qué te lleva a descubrir que estas sufriendo de acoso laboral? Primero se descubre la pérdida de la comunicación, pues la convivencia social es muy importante ya que afecta el desarrollo de las actividades y más porque las áreas laborales es donde pasamos la mayor parte de nuestro tiempo y se perturban las relaciones laborales, lo que afecta nuestra solvencia económica (Cortés Villegas, (s. f.).

Con el paso del tiempo y en base a las legislaciones que protegen a los trabajadores, algunas empresas han cambiado su estrategia del trato a los empleados y ahora se les incentiva a ser mejores cada día y luchar por metas e incentivos en el trabajo. Siendo resultado de las políticas públicas creadas e implementadas por las empresas que buscan mejorar la relación con sus empleados, en donde algunas destacan por elaborar y presentar propuestas para reformar la Ley Federal del Trabajo, entre las que se destacaron las de Coparmex, Concanaco y Canacintra, que buscaban alcanzar una mayor competitividad en los mercados. Las propuestas realizadas al Gobierno Federal, a través de la Secretaría del Trabajo y Previsión Social (STPS) se llevaron a cabo entre los años de 1989 y 2012 (Secretaría de Gobernación, 2013).
Fueron acciones para que los factores de la producción pudieran reunirse, discutir y elaborar propuestas para adecuar la legislación laboral y desarrollar alterativas de solución para el problema de muchos mexicanos.

Las reformas de los artículos laborales no han servido de mucho en la búsqueda de mejora del ambiente de trabajo, volviéndolo más agradable, aunque por una u otra cosa la mayoría de los trabajadores no tiene una comunicación sana entre los compañeros de trabajo. La pregunta sería ¿Qué se puede hacer para mejorar o deshacer el acoso laboral? esta es una pregunta muy complicada ya que es imposible tratar de que en cada empleo el trabajador se sienta confiable, seguro o contento con su desempeño, el estrés y la presión social son clave para que algunos trabajadores se desquiten con otro. Las cuestiones personales también influyen en el área del trabajo, entonces la segunda interrogante sería: ¿Quién tiene la responsabilidad de crear un ambiente de trabajo sano? para muchos la mayor responsabilidad es del encargado, jefe o titular de dicha empresa, a ellos les corresponde el crear un ambiente agradable para que así la producción y la energía de los trabajadores sea positiva y puede así tener una empresa redituable, 
entendiendo que la situación emocional de cada empleado influye en su desempeño laboral pero se debe considerar que la responsabilidad también le corresponde al trabajador, así que ambos tienen interés para que todo sea equilibrado.

Al analizar el comportamiento, sensibilidad y vulnerabilidad de los trabajadores tocamos un tema muy importante y a la vez controversial pues implica los sentimientos, pensamientos y sensibilidad de los trabajadores. Al sufrir el acoso laboral éste tiene un patrón de afectación que mencionamos con anterioridad, pero cabe destacar que puede derivar en consecuencias serias relacionadas con la salud tanto física como psicológica para la persona afectada. Esta modalidad de trabajo puede vulnerar de alguna manera los derechos fundamentales del trabajador por que la víctima llega a vivir en un estado de depresión constante, pues el acosador llega intimidar tanto a la víctima que este llega a un estado de desesperación. Algunos empleados tiene que soportar este tipo de actos por cuestiones de necesidad económica, lo que implica el depender de su empleo y no poder dejarlo y, esto empeora si el acosador consciente de la situación, sigue cometiendo el acoso laboral (mobbing) (Secretaría de Gobernación, 2013).

En la nota periodística referente el tema publicada por NOTIMEX en el periódico Excélsior, comentaban:

Los Diputados propusieron que practicar, permitir o tolerar la violencia verbal, física o psicológica en los centros de trabajo, será causa de multa o rescisión laboral. La Comisión de Trabajo y Previsión Social de la Cámara de Diputados aprobó reformas para incluir en la Ley Federal del Trabajo el concepto de acoso laboral o "mobbing", a fin de que sea considerado como una violación a los derechos de los trabajadores. $\mathrm{La}$ propuesta, que reforma distintos ordenamientos de las leyes Federal del Trabajo y General de Acceso de las Mujeres a una Vida Libre de Violencia, precisa que se entenderá como acoso laboral todo acto o comportamiento de violencia verbal, física o psicológica. Asimismo, las amenazas, la intimidación, las humillaciones, la discriminación y la explotación, así como amedrentar emocional $\mathrm{O}$ intelectualmente. De igual forma, atentar contra la autoestima, salud, integridad, libertad $\mathrm{o}$ seguridad de las o los trabajadores, de manera evidente o discreta, realizado por cualquier persona de superior, inferior o igual 
jerarquía. De acuerdo con las reformas, será causa de rescisión de la relación laboral, sin responsabilidad para el patrón, el cometer acoso laboral contra cualquier persona en el establecimiento o centro laboral. En tanto, será sin responsabilidad para el trabajador cuando el responsable del acto sea el patrón, sus familiares o cualquiera de sus representantes. Enfatiza que quedará prohibido a los patrones $\mathrm{o}$ a sus representantes permitir o tolerar actos de acoso laboral en el sitio de trabajo, además de que se les impondrá una multa que va de 250 a cinco mil veces la Unidad de Medida y Actualización. El dictamen señala que, según la Organización Internacional del Trabajo (OIT), el acoso laboral es "cualquier incidente en el cual una persona es abusada, maltratada en circunstancias relacionadas con su trabajo. Estas situaciones pueden ser originadas por jefes, compañeros de trabajo y en cualquier nivel de organización". En tanto, la Organización Mundial de la Salud (OMS) define el acoso laboral o "mobbing" como una situación de violencia o acoso recurrente dirigida hacia una persona. El objetivo de esa práctica es aislarlo de un grupo laboral, fenómeno que se caracteriza por conductas crueles $y$ hostiles que se convierten en una tortura psicológica para la víctima. Algunas manifestaciones de esto pueden ser rumores, difamación y calumnias, además de aislar o excluir a una persona, así como insultos o motes, ignorar o no dejar participar a una persona y/o amenazar. Las consecuencias para las víctimas se traducen en problemas psicológicos como angustia y depresión; físicos, como pérdida de peso, dolores de cabeza o insomnio; laborales, como bajo rendimiento y ausentismo, y sociales como problemas familiares $y$ pérdida de relaciones interpersonales (NOTIMEX, 2016).

\section{La Comisión del Trabajo y}

Previsión Social al tratar sobre las obligaciones del estado lo obligan a tipificar el delito de acoso laboral y de investigar, enjuiciar y eventualmente condenar a los responsables como parte de la obligación y de reparar todo el daño causado. He ahí donde los artículos que hablan sobre acoso laboral encuentran algunas lagunas. En los artículos actualizados no se habla o exige claramente la reparación del daño que el acosador le provoca a la víctima. En esta nota periodística se habla de la sanción que se le da a la empresa más no argumenta los daños causados a la víctima y como se puede reponer este 
daño. Basándonos en los lineamientos que conlleva el máximo órgano de justicia del país al establecer dicha norma se pueden llevar los casos de acoso laboral por la vía penal, civil o administrativa, ya que este problema se ha incrementado con los años, La causa de la anulación de un contrato u otra obligación legal de la relación laboral no implica responsabilidad para el patrón, si el acto se comete contra cualquier persona en el establecimiento o centro laboral. Por otro lado, será sin responsabilidad para el trabajador cuando el responsable del acto sea el patrón, sus familiares o cualquiera de sus representantes. No obstante, las acciones son más importantes que las palabras y es por eso que aunque la ley determine que el acoso laboral queda prohibido en la república mexicana por faltar claramente a las disposiciones aplicables de la ley, este tipo de situaciones se incrementa más con el paso de los años. Esto es una cuestión desequilibrada por que el patrón es el que se debería de hacerse responsable del ambiente laboral que rodea al trabajador.

Ya que queda prohibido a los patrones y sus representantes el realizar actos de hostigamiento y/o acoso sexual contra cualquier persona en el lugar del trabajo según la fracción Xll del artículo 133 (H. Congreso del Estado, 1970).

Este artículo es violado muchas veces, apoyado en el desconocimiento de los derechos de los trabajadores y el silencio que éstos mantienen sobre los actos que los acosadores arremeten contra ellos. El trabajador llega a vivir un infierno y con esto la calidad del trabajo de la víctima baja su rendimiento lo que sirve para aumentar más el acoso por su mal desempeño, llegando a intimidar. Los trabajadores que son víctimas llegan a vivir con miedo porque piensan que algo han hecho mal, se echan la culpa y debido a la continuidad de los malos tratos, llegan a considerar que no son capaces de realizar un trabajo correcto. En determinado momento puede que denuncien por miedo y temor de perder su trabajo aunque sienten que es muy difícil demostrar que está sufriendo acoso laboral. En muchos de los casos, los mismos compañeros de trabajo celebran cada humillación que su jefe o superior ejerce contra la víctima, así que nadie quiere apoyarlos con su testimonio en un juicio y abrir una carpeta de investigación. Una de las propuestas sería el asesorarse con un abogado para descubrir los pasos a realizar para denunciar que está sufriendo de acoso laboral y así entender 
cuál es el proceso que se realiza en este tipo de situación.

Analizar cuáles son los criterios que se deberán tomar en cuenta las personas para denunciar este tipo de delito, en el caso de acoso laboral el patrón es sancionado económicamente ya que si se llega a juicio y este lo pierde debe de indemnizar a la víctima que se le impondrá una multa por el equivalente de 250 a 5000 veces el salario mínimo que genera cualquier acto o conducta discriminatoria en el centro de trabajo al que realice acto de hostigamiento sexual o tolere o permita actos de acoso laboral en contra de sus trabajadores

En México se han incrementado los programas para prevenir y proteger los derechos del trabajador. Esto no ha ayudado a eliminar el delito de acoso laboral, pero la sociedad se beneficia con este tipo de información y les permite entender si ellos viven en su centro de trabajo este tipo de delito; es muy difícil poder sancionar o destituir de su cargo al acosador porque es el patrón y generalmente tiene influencia o soborna a la autoridad $\mathrm{y}$, en este punto, desafortunadamente el gobierno no le da mucha importancia y no logra defender los derechos de las personas y lograr salir ileso de este delito y no llega a ser sancionado; por ello si la víctima, en un dado caso, decide denunciar este abuso ante una autoridad, en lugar de encontrar apoyo y ayuda, paga las consecuencias y la autoridad no sanciona el delito. El empleado pierde su empleo y se ve afectado económicamente y en muchos de los casos llega a afectar la confianza que la víctima tenía en sí mismo.

\section{PROPUESTAS}

Para contrarrestar e informar a la población de cómo actuar frente a este tipo de delito se consideran viables las siguientes propuestas

- Crear alternativas de solución para frenar la discriminación de la mujer en el acoso laboral

- Crear pláticas donde el personal pueda opinar o comentar la relación de todos los empleados.

- Capacitar al personal para controlar sus emociones en las áreas del trabajo

- Reformar leyes para ser más claros y precisos sobre las sanciones del acoso laboral.

- Que el gobierno cada año haga reuniones con los directivos de cada empresa y evalúen el comportamiento de cada empleado. 
- Que el departamento de recursos humanos haga una evaluación minuciosa tanto física y mental al momento de contratar al empleado.

- Asesoría con un abogado para entender qué es el acoso laboral y cuál es el procedimiento que conlleva este delito.

- Informar a empleados sobre necesidad que las victimas para denunciar tienen que recabar todas las pruebas posibles para poder comprobar ante una autoridad el acoso laboral.

- Programas para prevenir y proteger los derechos del trabajador.

- Que las empresas implementen grupos de apoyo donde todos los empleados puedan describir su ambiente de trabajo.

- Que en cada empresa en un determinado tiempo se repartan volantes, se peguen carteles donde se le dé la información suficiente y explique de qué se trata el delito del acoso laboral.

- Proponer que las empresas les den a sus empleados pláticas psicológicas con el objetivo de proporcionar a los trabajadores el equilibrio integral para mejorar la convivencia en el trabajo, aprender a manejar sus emociones, elevar su autoestima, e invertir en su salud metal.

\section{CONCLUSIÓN}

El tema de acoso laboral es muy controversial, es algo que cada vez ocurre más en este país y desafortunadamente es un delito que atenta contra la dignidad de los empleados, ya que esto conlleva el sufrimiento de la víctima aunado al descredito de las autoridades del estado en materia laboral para frenar este acto. El gobierno mexicano siempre dice que es una aberración los que practican el acoso laboral al violar los derecho de los trabajadores (a). Al analizar el tema a fondo las autoridades que están encargadas de velar por nuestros derechos no han hecho nada para frenar y prevenir este tipo de conductas que la mayoría de las veces un superior ejerce sobre una empleada, así que es apremiante la continuidad de programas que hablen sobre el tema y se motive la cultura de la denuncia para coadyuvar a advertir que los limites en el trato hacia los trabajadores son necesarios para manejar una cultura de respeto y se 
enfoquen en un mejor desenvolvimiento laboral que reditúe en ganancias económicas para todos.

Podemos resumir que el acoso laboral en México es un problema que va en incremento con el paso del tiempo y que llega a ser un problema social; el mobbing es una práctica indignante que llega a dañar tanto física como psicológicamente al trabajador al recibir agresiones y ser victimizado, pues ve denigrada su dignidad junto con sus derechos laborales.

El delito del acoso laboral es muy difícil de combatir porque el ambiente de trabajo puede ser confundido con aquél en donde las exigencias son muy fuertes. En cada empresa, cada persona tiene su personalidad, su manera de pensar, sus cambios de humor, su manera de ver las cosas y actualmente la presión laboral es una situación que la mayoría de los mexicanos vive en sus empleos $\mathrm{y}$ desafortunadamente, los limites se rompen y la gran mayoría de las víctimas no se pueden defender porque dependen enormemente del ingreso económico y no pueden perderlo debido a la necesidad económica, lo que orilla a la víctima a aguantar y soportar todas las agresiones y humillaciones para conservar su trabajo. Esto afecta a las familias mexicanas, que viven esa situación de estrés sin saber la situación difícil que vive la víctima directamente en secreto y que los afecta a todos.

\section{REFERENCIAS IBLIOGRÁFICAS.}

Arciniega, Rosa Silvia; (2009). El Acoso Moral (Mobbing) en las Organizaciones Laborales. Psicología

Iberoamericana, Julio-Diciembre, 1323. Recuperado en http://www.redalyc.org/articulo.oa?id=1 $\underline{33912609003}$

Cámara de Diputados del H. Congreso de la Unión, (1917). Constitución Política de los Estados Unidos Mexicanos. Diario Oficial de la Federación. Última Reforma DOF 2402-2017. Recuperado en http://www.diputados.gob.mx/LeyesBib lio/pdf/1_240217.pdf , (1970). Ley Federal del Trabajo. Diario Oficial de la Federación. Última Reforma DOF 12-06-2015. Recuperado en http://www.diputados.gob.mx/LeyesBib lio/pdf/125_120615.pdf 


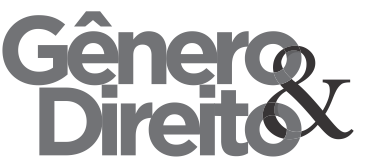

Carrasco Fernández, (2012).

Discriminación Laboral por motivos de género. Universidad Nacional Autónoma de México. Biblioteca Jurídica Virtual del Instituto de Investigaciones Jurídicas de la UNAM. Recuperado en https://archivos.juridicas.unam.mx/ww w/bjv/libros/7/3142/8.pdf

Cortés Villegas, (s. f.). El mobbing: Síndrome de Heinz Leymann. Colegio Mexicano del Derecho en la Seguridad Social. Recuperado en http://www.izt.uam.mx/sotraem/Docum entos/AMET2011/REC/TEXTO/10/10 08.pdf

Instituto Nacional de Estadística y Geografía [INEGI], (2011). Panorama de Violencia contra las mujeres en Tabasco. Encuesta Nacional sobre la Dinámica de las Relaciones en los Hogares, ENDIREH 2011. ISBN 978607-494-691-8. Recuperado en http://internet.contenidos.inegi.org.mx/c ontenidos/productos/prod_serv/contenid os/espanol/bvinegi/productos/nueva_est ruc/702825051228.pdf

Martínez León, Irurtia Muñiz, Camino Martínez León, Torres Martin y Queipo Burón, (2012). El acoso psicológico en iódico do Núcleo de Estudos e Pesquisas sobre Gênero e Direito Centro de Ciências Jurídicas - Universidade Federal da Paraíba V. 6 - No 03 - Ano 2017 (Spanish Edition)

el trabajo o Mobbing: patología emergente. Mobbing in the workplace: emergent pathology. Gaceta Internacional de Ciencias Forenses. $\mathrm{N}^{\mathrm{o}} 3$. ISSSN 2174-9019. Recuperado en http://www.uv.es/gicf/3Ar1_Mtz_Leon_ GICF_03.pdf

NOTIMEX, (2016). Avalan reformas para castigar el acoso laboral. Excelsior. Grupo Imagen Medios de Comunicación, S. A. de C. V. Recuperado en http://www.excelsior.com.mx/nacional/ $\underline{\text { 2016/11/02/1125817\#view-5 }}$

Robbins y Judge, (2009). Comportamiento Organizacional. Decimotercera edición. San Diego State University y University of Florida. Pearsons Educación, México. ISBN: 978-607-442-098-2. Recuperado en https://psiqueunah.files.wordpress.com/ 2014/09/comportamiento-

organizacional-13a-ed-_nodrm.pdf

Secretaría de Gobernación [SEGOB], (2013). Reforma laboral, derecho del trabajo y justicia social en México. Unidad de Asuntos Jurídicos. Primera Edición. ISBN: 978-607-427-217-8. Recuperado en 
http://ordenjuridico.gob.mx/Publicacion

es/Libros2013/laboral-2013-web.pdf

Sieglin, (2016). Acoso Laboral y

culturas organizacionales. Ciencia y

Sociedad.

Universidad Autónoma de Nuevo León.

Año 19, $\mathrm{N}^{\mathrm{o}}$ 80. Recuperado en

http://eprints.uanl.mx/11365/1/Docume

$\underline{\text { nto0.pdf }}$ 